\title{
USING A SPLIT-WINDOW ALGORITHM FOR THE RETRIEVAL OF THE LAND SURFACE TEMPERATURE VIA LANDSAT-8 OLI/TIRS
}

\author{
Chavarit AUNTARIN $^{1(\mathbb{D})}$, Poramate CHUNPANG ${ }^{2}$ (D), Wutthisat CHOKKUEA ${ }^{3}$ (D) \\ and Teerawong LAOSUWAN ${ }^{4 *(D)}$
}

DOI: 10.21163/GT_2021.163.03

\begin{abstract}
:
Climate change has worsened and has widespread impact. This is partly due to the release of greenhouse gases from human activities, which cause the greenhouse effect. This leads to the global temperature rising to an unusual level, otherwise known as global warming. This study aimed to use a split-window algorithm to retrieve the land surface temperature via Landsat-8 OLI/ TIRS data in the Roi Et province area. The research methodology included 1) separating the Landsat-8 OLI data into four types of land use, i.e. the agricultural, forest, urban and water areas and 2) the data for Landsat-8 OLI bands 4 and 5 and Landsat- 8 TIRS (bands 10,11) being analysed to retrieve the land surface temperature using a split-window algorithm. The results from the land-use separation showed that the total area of Roi Et was 8,299.46 $\mathrm{km}^{2}$ divided into a 4,787 $\mathrm{km}^{2}$ agricultural area, which accounted for $60.81 \%$; a $1,555 \mathrm{~km}^{2}$ forest area, accounting for $19.75 \%$; a $1,212 \mathrm{~km}^{2}$ urban area, accounting for $15.39 \%$ and a $317.44 \mathrm{~km}^{2}$ water area, accounting for $4.03 \%$. The land surface temperature analysis result using a split-window algorithm indicated that the average temperature of Roi Et was $34.74^{\circ} \mathrm{C}$. Moreover, it was found that the land surface temperature of the urban area had the highest mean land surface temperature, followed by the forest area, the agricultural area and the water source area, respectively.
\end{abstract}

Key-words: Remote Sensing, Land Surface Temperature, Split-Window Algorithm, Landsat-8 OLI/TIRS, Normalised Difference Vegetation Index (NDVI), Fractional Vegetation Cover (FVC)

\section{INTRODUCTION}

The global environmental crises that cause the most damage and harm to humans are weather changes, which refers to the change in average weather conditions in relation to the temperature, wind, rain, etc., whether the cause is human activities or natural variation, especially when the average temperature on earth appears to be higher, which is known as global warming whereby the world cannot emit heat from solar energy in the normal way. Based on such reason, the earth average temperature seems to be higher. However, in the past century, the average temperature was higher by a small degree. The world's weather and environmental conditions have changed considerably and had a severe effect on living things (Lemke et al., 2007; IPCC, 2019). Thailand is an economic and industrial developing country that has changed agricultural land into industrial land continually within the last two to three decades (Dechaphongthana et al., 2016). Generally, the temperature of the agricultural area is higher than the forest temperature, but it is lower than the urban area full of buildings (Zhang et al., 2010; Mathew et al., 2017). Such progress has affected a growing number of communities, residences, commercial buildings and factories. Meanwhile, it has led to green areas needing to absorb sunlight and convert it into energy via a decreased photosynthesis process, contributing to warmer temperatures in urban areas and the eventual formation of the urban heat island phenomenon (Laosuwan et al., 2017; Rotjanakusol \& Laosuwan, 2018).

Studying the land surface temperature is considered as another form of detecting heat on the earth's surface, and it is currently widely used to monitor the global temperature. The land surface temperature is most likely utilised in various aspects, such as studying the increasing global

1,2, 3, 4 Department of Physics, Faculty of Science, Mahasarakham University, Maha Sarakham, 44150,

Thailand, chavarit.py@gmail.com,poramate_c@hotmail.com,drwutthisat@gmail.com

*Corresponding author: teerawong@msu.ac.th 
temperature, which is caused by weather changes; studying weather conditions by detecting an increase in the atmospheric concentrations of green-house gases that effect the land surface temperature; studying the increase in the land surface temperature, which affects North Pole icebergs, and studying the land surface temperature, which effects plants in the ecosystem of different regions around the world (Li et al., 2013; Mukhelif et al., 2016; Miles \& Esau, 2017; Khandelwal et al., 2018; Nill et a., 2019; Capodici et al., 2020). Regarding studying and searching for research papers and documents relevant to land surface temperature analysis, a lot of the research was conducted on land surface temperature analysis using satellite data, such as the land surface temperature change in urban areas (Rotjanakusol \& Laosuwan, 2020), the study on the urban heat island phenomenon in atmospheric layers (Prohmdirek et al., 2020) and the detection and identification of wildfire areas using the land surface temperature (Vlassova et al., 2014).

In addition, many research studies currently focus on developing a method to detect the land surface temperature using remote sensing technology. Remote sensing technology is accepted as being modern and efficient, and it can be applied to rapidly monitor and detect global phenomena (Uttaruk \& Laosuwan, 2018; Rotjanakusol \& Laosuwan, 2019; Rotjanakusol \& Laosuwan, 2020; Uttaruk \& Laosuwan, 2020). In the meantime, many research papers have indicated using a mathematical model in conjunction with remote sensing technology to analyse the land surface temperature, such as radiative transfer equation (RTE), Mono-Window (MW), split window (SW), Dual-Angle (DA) and single-channel (SC) (Ren et al., 2011; Yu et al., 2014; Chen et al., 2015; Du et al., 2015). Furthermore, the land surface temperature from satellite data by thermal infrared emissivity can clearly show differences in land surface temperature with land use and land cover such as residential area, community area, industrial plant, open area, including the burned area in the agricultural area are relatively high land surface temperature. In addition, forests area, agricultural area, aquaculture area, wetlands, and water bodies, the land surface temperature are relatively low (Valor \& Caselles, 1996). The estimation land surface temperature using a split window was first applied to the sea surface temperature estimation (Mcmillin, 1975) when two thermal infrared wavelengths were carried out at a wavelength of 10.5-12.5 $\mu \mathrm{m}$ (band 10 and band 11), come to use it efficiently and satisfactorily. Because the influence of water vapour in the atmosphere is removed from the brightness temperature of the two wavelengths.

Due to the importance of the earlier mentioned weather change and the global temperature increase, this study aims to focus on using a split-window algorithm for the retrieval of the land surface temperature via Landsat-8 OLI/TIRS data in the Roi Et province area. The expected results will be to understand the land surface temperature and its change according to land use in Roi Et.

\section{MATERIALS AND METHODS}

Roi Et (Fig. 1) consists of 20 districts. It is located in the middle part of the northeast region of Thailand between latitudes of $15^{\circ} 24^{\prime}$ to $16^{\circ} 19^{\prime}$ and longitudes of $103^{\circ} 17^{\prime}$ to $104^{\circ} 22^{\prime}$ with a total area of $8,299.46 \mathrm{~km}^{2}$, ranking it the $10^{\text {th }}$ of the region and the $23^{\text {rd }}$ of the country. Most of the province is covered by high plains of about $120-160$ metres above mean sea level. The average temperature throughout the year is about $26.9^{\circ} \mathrm{C}$, the average low temperature $22.5^{\circ} \mathrm{C}$ and the average maximum temperature $32.3^{\circ} \mathrm{C}$. It has three seasons: the summer is hot and dry, which lasts from February to April; the rainy season lasts from May to September, but the rain is irregular, and the annual rainfall is approximately $1,200 \mathrm{~mm} / \mathrm{y}$; and it is cold in winter, which lasts from October to January.

\subsection{Data}

The study used Landsat-8 OLI/TIRS data (Table 1), which were recorded on 16 December 2018. Landsat-8 OLI/TIRS was launched on 13 February 2013 and orbits the earth every 99 minutes. The satellite travels over both the North and South Poles at an altitude of $705 \mathrm{~km}$. It has bands for capturing the response of the earth's surface at discrete wavelengths, i.e. coastal aerosol, blue, green, red, NIR for one wavelength range and SWIR for two wavelength ranges. The spatial resolution of Landsat-8 OLI is 30 metres pixel size resolution in TIRS band, two wavelength ranges and 100 metres pixel size resolution, a panchromatic band, one wavelength range and 15 metres pixel size resolution. 
Table 1.

Landsat-8 OLI/TIR bands information.

\begin{tabular}{lcc}
\hline Wavelength $(\boldsymbol{\mu m})$ & Sensor & Description \\
\hline Band 1: 0.43-0.45 & Operational Land Imager (OLI) & Coastal aerosol \\
Band 2: 0.45-0.51 & Operational Land Imager (OLI) & Blue \\
Band 3: $0.53-0.59$ & Operational Land Imager (OLI) & Green \\
Band 4: 0.64-0.67 & Operational Land Imager (OLI) & Red \\
Band 5: 0.85-0.88 & Operational Land Imager (OLI) & NIR \\
Band 6:1.57-1.65 & Operational Land Imager (OLI) & SWIR 1 \\
Band 7: 2.11-2.29 & Operational Land Imager (OLI) & SWIR 2 \\
Band 8: $0.50-0.68$ & Operational Land Imager (OLI) & Panchromatic \\
Band 9: $1.36-1.38$ & Operational Land Imager (OLI) & Cirrus \\
Band 10:10.60-11.19 & Thermal Infrared Sensor (TIRS) & TIRS 1 \\
Band 11: $11.50-12.51$ & Thermal Infrared Sensor (TIRS) & TIRS 2 \\
\hline
\end{tabular}

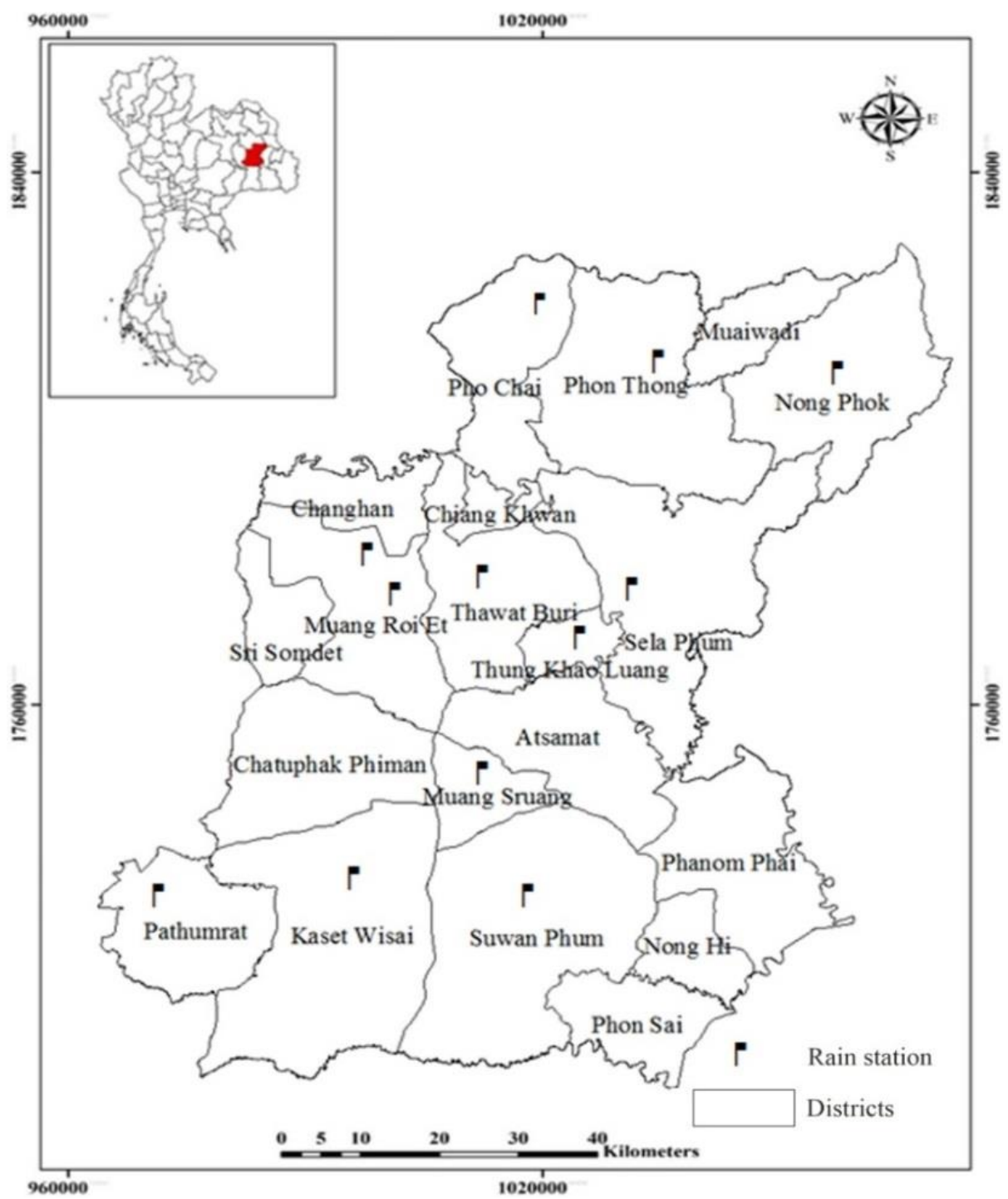

Fig. 1. Study area 


\subsection{Temperature Data from Ground Station}

This study collected the daily temperature data from the Thai Meteorological Department (TMD) station located in Roi Et at the same time as the satellite data collection.

\subsection{Procedures for Land-use Separation}

Land use in Roi Et is separated by Landsat-8 OLI data (band 3(B) 4(G) 5(R)) into four types: the agricultural, forest, urban and water areas. The reflectance value called a digital number that the satellite recorded for categorising the layers of data to show the physical differences of the objects. A supervised classification method and a general statistical method - the maximum likelihood - were used to separate the land use (Zhang et al., 2007).

\subsection{Procedures for Temperature Analysis}

The land surface temperature analysis from Landsat-8 OLI/TIRS data using split-window algorithms that use a Quantum GIS (QGIS) software package can be divided, as shown in Fig. 2, and is detailed below:

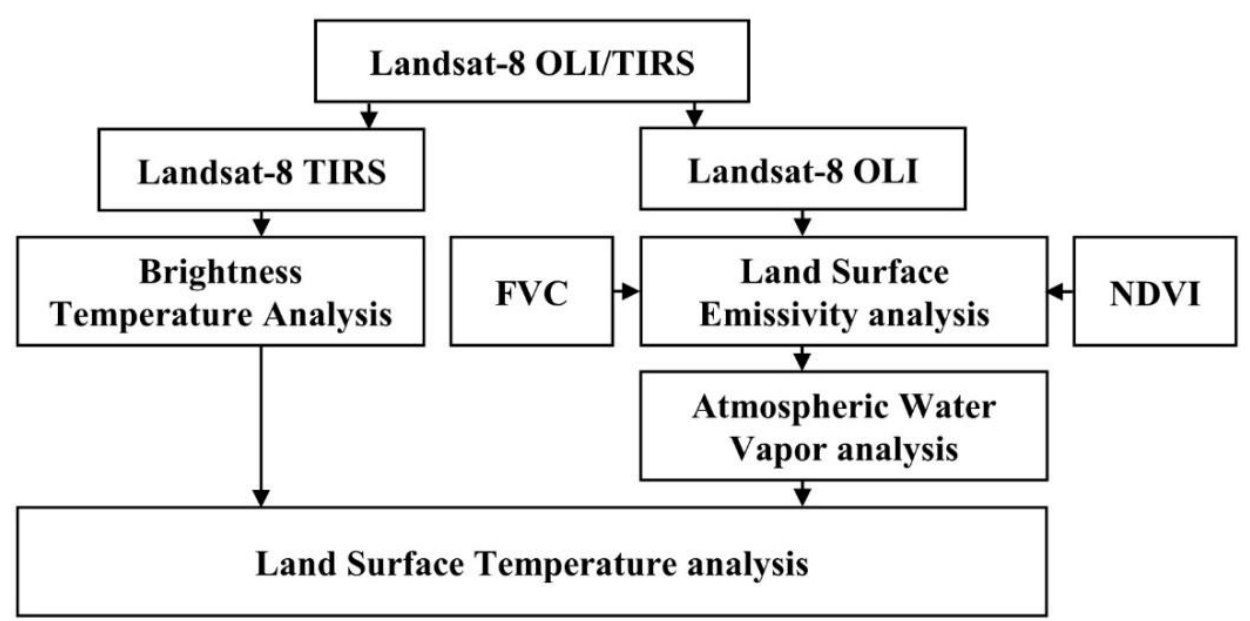

Fig. 2 Procedures for land surface temperature analysis

\subsubsection{Brightness Temperature Analysis}

The land surface temperature was analysed in the wavelength range of thermal infrared sensors (TIRS) (bands 10 and 11) when the radiance of the objects was equal to the black body radiation. Black body radiation determines the brightness temperature values of the objects on the earth. Furthermore, the objects' radiance will depend on the electromagnetic wavelength that interacts with the objects, and it is the proportion between the reflection, absorption and transmission. The methods of the brightness temperature analysis are shown in Equations 1 and 2 and Table 2 (Barsi et al., 2014).

$$
\mathrm{T}=\frac{\mathrm{k}_{2}}{\operatorname{In}\left(\frac{\mathrm{k}_{1}}{\mathrm{~L}_{\lambda}}+1\right)}
$$

Where:

$\mathrm{T}=$ The brightness temperature in Kelvin $(\mathrm{K})$

$\mathrm{k}_{1}=$ The constant value of Landsat -8 TIRS (band 10=774.89 and band $11=480.89$ ) 
$\mathrm{k}_{2}=$ The constant value of Landsat- 8 TIRS (band 10=1321.08 and band $11=1201.14$ )

$\mathrm{L}_{\lambda}=$ The TOA spectral radiance (Watts $\left./\left(\mathrm{m}^{2} * \operatorname{srad} * \mu \mathrm{m}\right)\right)$

$$
\mathrm{L}_{\lambda}=\mathrm{M}_{\mathrm{L}} \mathrm{Q}_{\mathrm{cal}}+\mathrm{A}_{\mathrm{L}}
$$

Where:

$\mathbf{M}_{\mathrm{L}}=$ The band-specific multiplicative rescaling factor from the metadata

$A_{L}=$ The band-specific additive rescaling factor from the metadata

$\mathrm{Q}_{\mathrm{cal}}=$ The quantised and calibrated standard product pixel values (DN)

Rescaling factor values.

Table 2.

\begin{tabular}{cc}
\hline Rescaling factor & Band 10 and Band 11 \\
\hline $\mathrm{M}_{\mathrm{L}}$ & 0.000342 \\
\hline $\mathrm{A}_{\mathrm{L}}$ & 0.1 \\
\hline
\end{tabular}

\subsubsection{Land Surface Emissivity Analysis}

This is an analysis of the radiation emitted by real objects on the earth that cannot absorb all the energy, but they can emit a small amount of radiation compared to a black body. Emissivity can be estimated from the proportion of the plants that extend into the soil that is obtained from the Normalised Difference Vegetation Index (NDVI). The land surface emissivity analysis is shown in Equation 3 (Rajeshwari \& Mani, 2014). Based on Equation 3, it is necessary to firstly analyse the fractional vegetation cover (FVC) value, as shown in Equation 4 (Laosuwan \& Uttaruk, 2014). The NDVIs and NDVIv are values of the NDVI for bare soil (NDVIs = Minimum value of the NDVI) and pure green vegetation (NDVIv = maximum value of the NDVI). The FVC value is the plant fertility analysis, whose result is taken from the NDVI, as shown in Equation 5 (Uttaruk \& Laosuwan, 2017), while $\mathrm{p}$ is the reflectance value of electromagnetic radiation from land cover, which depends on the wavelength and the proportion of the reflection, absorption and transmission. The analysis method is shown in Equation 6.

$$
\mathrm{LSE}=\varepsilon_{\mathrm{s}}(1-\mathrm{FVC})+\varepsilon_{\mathrm{v}} * \mathrm{FVC}
$$

Where:

$\varepsilon_{\mathrm{s}}=$ The constant value of Landsat- 8 (band $10=0.971$ and band $11=0.977$ )

$\varepsilon_{\mathrm{v}}=$ The constant value of Landsat -8 (band $10=0.987$ and band $11=0.989$ )

$$
\mathrm{FVC}=\frac{\mathrm{NDVI}^{-N D V I}}{\mathrm{NDVI}_{\mathrm{v}}-\mathrm{NDVI}_{\mathrm{s}}}
$$

Where:

$\mathrm{NDVI}_{\mathrm{v}}=$ The maximum value of NDVI

$\mathrm{NDVI}_{\mathrm{s}}=$ The minimum value of NDVI

$$
\mathrm{NDVI}=\frac{\rho_{\mathrm{NIR}}-\rho_{\mathrm{Red}}}{\rho_{\mathrm{NIR}}+\rho_{\mathrm{Red}}}
$$


Where:

$\rho_{\mathrm{NIR}}=$ The reflection value of vegetation in the near infrared wave range (NIR)

$\rho_{\text {Red }}=$ The reflection value of vegetation in the red wave range (RED)

$\rho=$ The reflection value of the soil cover

$$
\rho_{\lambda}=\mathrm{M}_{\rho} \mathrm{Q}_{\mathrm{cal}}+\mathrm{A}_{\rho}
$$

Where:

$M_{\rho}=$ The reflectance multiplicative scaling factor

$\mathrm{A}_{\rho}=$ The reflectance additive scaling factor

$\mathrm{Q}_{\text {cal }}=$ The digital number (DN)

\subsubsection{Atmospheric Water Vapour Analysis}

Atmospheric water vapour analysis can be analysed from electromagnetic radiation in the thermal infrared sensors (TIRS) wavelength range, which travels through atmospheric layers with a brightness temperature value calculation on bands 10 and 11 of Landsat 8 (TIRS 1 wavelength range between $10.60-11.19 \mu \mathrm{m}$ and TIRS 2 wavelength range between $11.50-12.51 \mu \mathrm{m}$, respectively). The analysis method is shown in Equation 7 (Ren et al., 2015).

$$
\mathrm{WV}=\mathrm{a}+\mathrm{b} \times \tau_{\mathrm{j}} / \tau_{\mathrm{i}}
$$

Where:

$$
\frac{\tau_{j}}{\tau_{i}} \approx R_{j i}=\sum_{k=1}^{N}\left(T_{i, j}-\bar{T}\right)\left(T_{i, j}-\bar{T}\right) / \sum_{k=1}^{N}\left(T_{i, j}-\bar{T}\right)^{2}
$$

Where:

$a$ and $b$ are the coefficients of the model

$\tau=$ The electromagnetic wave's transmission ability through the atmosphere (bands 10 and 11)

$i, j=$ Bands 10 and 11

$T_{i, j}, T_{j, k}=$ The brightness temperature of bands 10 and 11

$\bar{T}_{i}, \bar{T}_{j}=$ The mean brightness temperature of bands 10 and 11

\subsubsection{Land Surface Temperature Analysis}

In this study, the land surface temperature analysis using a split-window algorithm was conducted from (1) the brightness temperature value calculation on bands 10 and 11, (2) the land surface emissivity value of bands 10 and 11 and (3) the atmospheric water vapour analysis result. The analysis method is shown in Equation 8 and Table 3 (Yue et al., 2007).

$$
\mathrm{LST}=\left(\mathrm{T}_{10}+\mathrm{C}_{10}-\mathrm{T}_{11}\right)+\left(\mathrm{T}_{10}-\mathrm{T}_{11}\right)^{2} \mathrm{C}_{0}+\left(\mathrm{C}_{3}+\mathrm{C}_{4} \mathrm{~W}\right)(1-\varepsilon)+\left(\mathrm{C}_{5}+\mathrm{C}_{6} \mathrm{~W}\right) \Delta \varepsilon
$$

Where:

$\mathrm{T}_{10}, \mathrm{~T}_{11}=$ The brightness temperature of bands 10 and 11

$\varepsilon=$ The mean land surface emissivity of bands 10 and 11

$\Delta \varepsilon=$ The difference land surface emissivity of bands 10 and 11

$\mathrm{C}_{0}-\mathrm{C}_{6}=$ The constant value (see in Table 3)

$\mathrm{W}=$ The atmospheric water vapours 
Table 3.

The coefficient of the split-window algorithm.

\begin{tabular}{cc}
\hline Constant & Value \\
\hline $\mathrm{C} 0$ & -0.678 \\
\hline $\mathrm{C} 1$ & 1.378 \\
\hline $\mathrm{C} 2$ & 0.183 \\
\hline $\mathrm{C} 3$ & 54.30 \\
\hline $\mathrm{C} 4$ & -2.238 \\
\hline $\mathrm{C} 5$ & -129.2 \\
\hline $\mathrm{C} 6$ & 16.40 \\
\hline
\end{tabular}

\section{RESULTS AND DISCUSSIONS}

The method of acquiring the land surface temperature from Landsat-8 OLI/TIRS data using the SWA method is shown below:

\subsection{Result of land-use Separation}

The landsat-8 OLI data were recorded on 16 December 2018 and brought to separate land use into four types: the agricultural, forest, urban and water areas, as seen in Fig. 3.

The result of the land-use separation using supervised classification and maximum likelihood methods revealed that Roi Et was separated into a $4,787 \mathrm{~km}^{2}$ agricultural area, accounting for $60.81 \%$; a $1,555 \mathrm{~km}^{2}$ forest area, accounting for $19.75 \%$; a $1,212 \mathrm{~km}^{2}$ urban area, accounting for $15.39 \%$ and a $317.44 \mathrm{~km}^{2}$ water area, accounting for $4.03 \%$. To validate the land use accuracy in this study, the sampling point was selected using a random method, and it required every land-use group to be worth at least 10 validation points. In this case, the confidence value of $95 \%$ was assigned a number of points for the verification of 200 points. The result showed that the overall accuracy was $94 \%$, and the kappa coefficient was 0.92. In addition, it was found that the land-use groups that obtained producer's accuracy and user's accuracy were the agriculture, urban, water and forest areas with values of 95.50, 95.30, 94.80 and 94.60, respectively. The results of the land-use validation in this study are shown in Table 4.

Furthermore, when the land-use separation data were analysed at a district level (Table 5), it was found that most lands are agricultural areas.

(1) The top three districts with the largest agricultural areas per the whole area of the districts were Kaset Wisai at $1.07 \mathrm{~km}^{2}$, accounting for $78.24 \%$; Mueang Suang at $0.19 \mathrm{~km}^{2}$, accounting for $76.81 \%$ and Suwanna Phum at $0.99 \mathrm{~km}^{2}$, accounting for $73.16 \%$.

(2) The top three districts with the largest forest areas per the whole area of the districts were Phon Thong at $0.31 \mathrm{~km}^{2}$, accounting for $28.52 \%$; Nong Phok at $0.27 \mathrm{~km}^{2}$, accounting for $30.44 \%$ and Suwanna Phum at $0.23 \mathrm{~km}^{2}$, accounting for $17.15 \%$.

(3) The top three districts with the largest urban areas per the whole area of the districts were Phon Thong at $0.30 \mathrm{~km}^{2}$, accounting for $27.10 \%$; Nong Phok at $0.27 \mathrm{~km}^{2}$, accounting for $30.39 \%$ and Phochai at $0.15 \mathrm{~km}^{2}$, accounting for $24.89 \%$.

(4) The top three districts with the largest water area per the whole area of the districts were Sela Phum at $0.16 \mathrm{~km}^{2}$, accounting for $13.26 \%$; Phanom Phai at $0.04 \mathrm{~km}^{2}$, accounting for $6.09 \%$ and Thawat Buri at $0.03 \mathrm{~km}^{2}$, accounting for $5.25 \%$. 


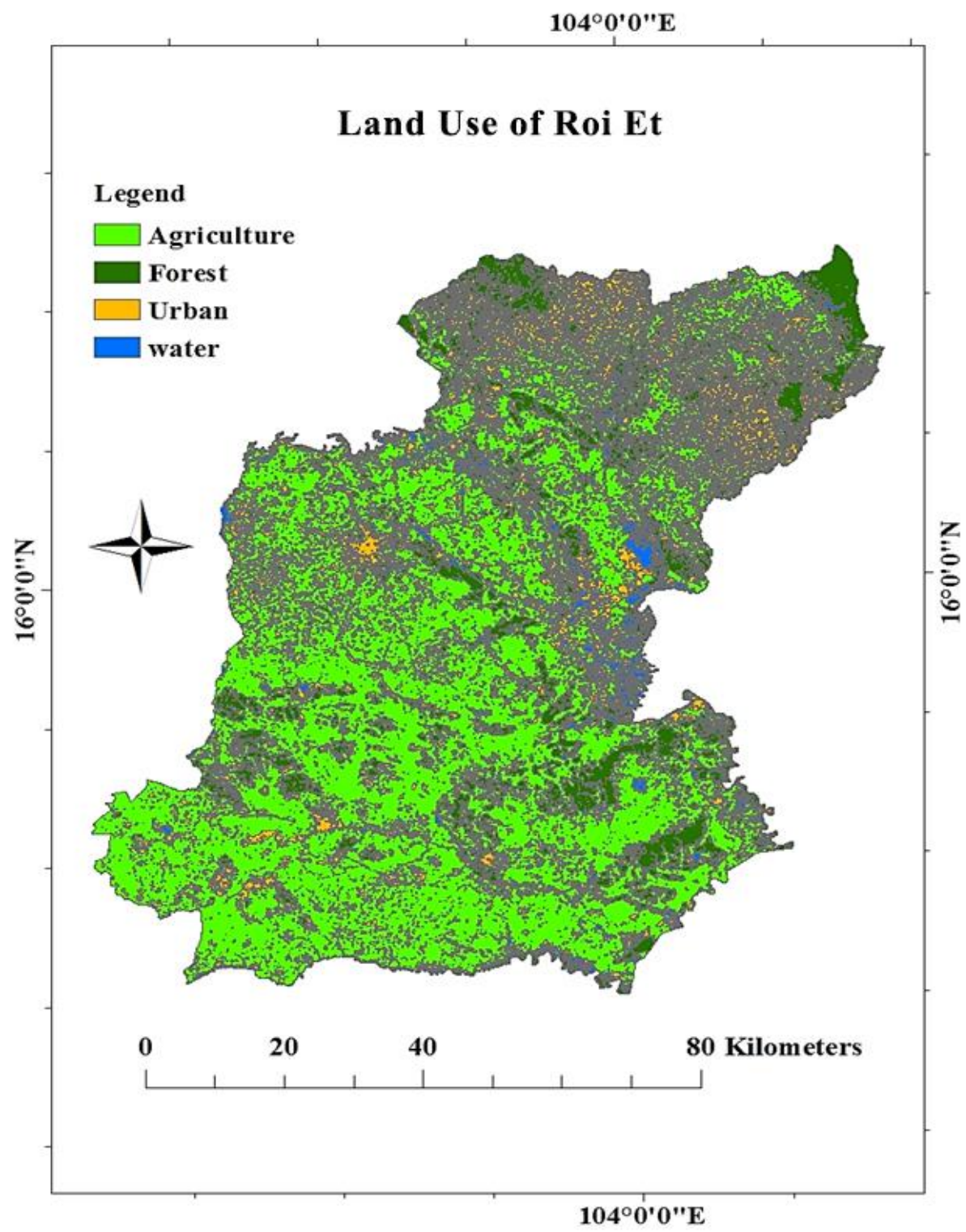

Fig. 3. Separate land use of Roi Et province.

Land surface temperature analysis separated by districts.

Table 4.

\begin{tabular}{ccc}
\hline Land-use classification & Producer's accuracy & User's accuracy \\
\hline Agriculture area & 95.50 & 95.01 \\
Forest area & 94.60 & 94.60 \\
Urban area & 95.30 & 95.00 \\
Water area & 94.80 & 95.28 \\
\hline Overall accuracy & $94.00 \%$ \\
\hline Kappa coefficient & 0.92 \\
\hline
\end{tabular}


Table 5.

Land surface temperature analysis separated by districts.

\begin{tabular}{lccccc}
\hline \multicolumn{1}{c}{ Districts } & $\begin{array}{c}\text { Agricultural } \\
\left(\mathbf{k m}^{\mathbf{2}}\right)\end{array}$ & $\begin{array}{c}\text { Urban } \\
\left(\mathbf{k m}^{\mathbf{2}}\right)\end{array}$ & $\begin{array}{c}\text { Forest } \\
\left(\mathbf{k m}^{\mathbf{2}}\right)\end{array}$ & $\begin{array}{c}\text { Water } \\
\left(\mathbf{k m}^{\mathbf{2}}\right)\end{array}$ & $\begin{array}{c}\text { Temperature } \\
\left({ }^{\circ} \mathbf{C}\right)\end{array}$ \\
\hline Atsamat & 270.46 & 47.00 & 90.00 & 12.00 & 34.00 \\
\hline Changhan & 118.07 & 24.17 & 26.71 & 15.24 & 34.00 \\
\hline Chaturaphak Phiman & 365.60 & 40.25 & 73.50 & 7.32 & 35.27 \\
\hline Chiang Khwan & 44.20 & 7.04 & 7.61 & 8.70 & 34.80 \\
\hline Kaset Wisai & 667.08 & 88.69 & 83.00 & 13.93 & 36.00 \\
\hline Muai Wadi & 85.04 & 41.38 & 41.04 & 2.37 & 33.80 \\
\hline Muang Roi Et & 314.35 & 68.40 & 61.07 & 6.21 & 34.80 \\
\hline Muang Sruang & 119.07 & 10.67 & 23.46 & 1.87 & 35.00 \\
\hline Nong Hi & 95.27 & 10.38 & 44.89 & 4.91 & 34.20 \\
\hline Nong Phok & 211.65 & 169.93 & 170.19 & 9.11 & 34.00 \\
\hline Pathumrat & 237.45 & 47.06 & 48.87 & 11.68 & 36.00 \\
\hline Phanom Phai & 238.35 & 43.01 & 131.88 & 26.89 & 33.40 \\
\hline Phochai & 134.30 & 93.62 & 137.21 & 10.85 & 34.50 \\
\hline Phon Sai & 166.57 & 15.76 & 28.50 & 19.84 & 34.24 \\
\hline Phon Thong & 289.76 & 185.25 & 194.90 & 13.45 & 35.00 \\
\hline Sela Phum & 429.30 & 90.26 & 130.44 & 99.37 & 33.50 \\
\hline Sri Somdet & 108.44 & 39.01 & 12.32 & 4.62 & 35.07 \\
\hline Suwanna Phum & 621.01 & 63.00 & 145.62 & 19.07 & 35.74 \\
\hline Thawat Buri & 303.74 & 45.43 & 68.72 & 23.18 & 35.53 \\
\hline Thung Kao Luang & 50.42 & 13.58 & 20.43 & 6.83 & 36.00 \\
\hline
\end{tabular}

\subsection{Land Surface Temperature Analysis Result}

The analysis result of Roi Et's land surface temperature using Landsat-8 OLI/TIRS data with a split-window algorithm is shown in Fig. 4.

\subsection{Analysis Result of Temporal Variation of Land Surface Temperature}

The analysis result of the temporal variation between the land surface temperature and the types of land use in Roi Et based on Landsat-8 OLI/TIRS data is shown in Fig. 5. It shows that Roi Et has 20 districts, as indicated by the graph on the $\mathrm{x}$-axis, which shows that there are districts whose land use was separated into four types: 1) agricultural area, 2) forest area, 3) urban area and 4) water source area. The research hypothesis was that the urban area of each district has a higher temperature than other areas in the land use. The graph on the y-axis on the left shows the area size of the land use in $\mathrm{km}^{2}$, and the right side shows the temperature in ${ }^{\circ} \mathrm{C}$. From Fig. 4, it can be seen that the temperature graph changes according to the types of land use in each district. The findings from the study revealed that the three districts with a maximum land surface temperature in urban areas were Kaset Wisai, Pathumrat and Thung Khao Luang, where the land surface temperature was $36.00^{\circ} \mathrm{C}$. 
The top three districts with a minimum land surface temperature in urban areas were Phanom Phrai, Sela Phum and Moei Wadee, where the land surface temperatures were $33.40^{\circ} \mathrm{C}, 33.50^{\circ} \mathrm{C}$ and $33.80^{\circ} \mathrm{C}$, respectively. The land surface temperature analysis result was associated with land use; namely, the analysed land surface temperature in urban areas showed the maximum value, followed by the agricultural, forest and water source areas, respectively. Furthermore, in remote sensing technology, the detector measures the electromagnetic radiation that reflects from the earth's surface material. These measurements can help distinguish the type of land that is covered. Soil, water and vegetation have distinctly different reflections and absorption patterns at different wavelengths. The reflected of radiation from a surface material, such as soil, varies with the range of wavelengths in the electromagnetic spectrum. This is known as a material spectral signature.

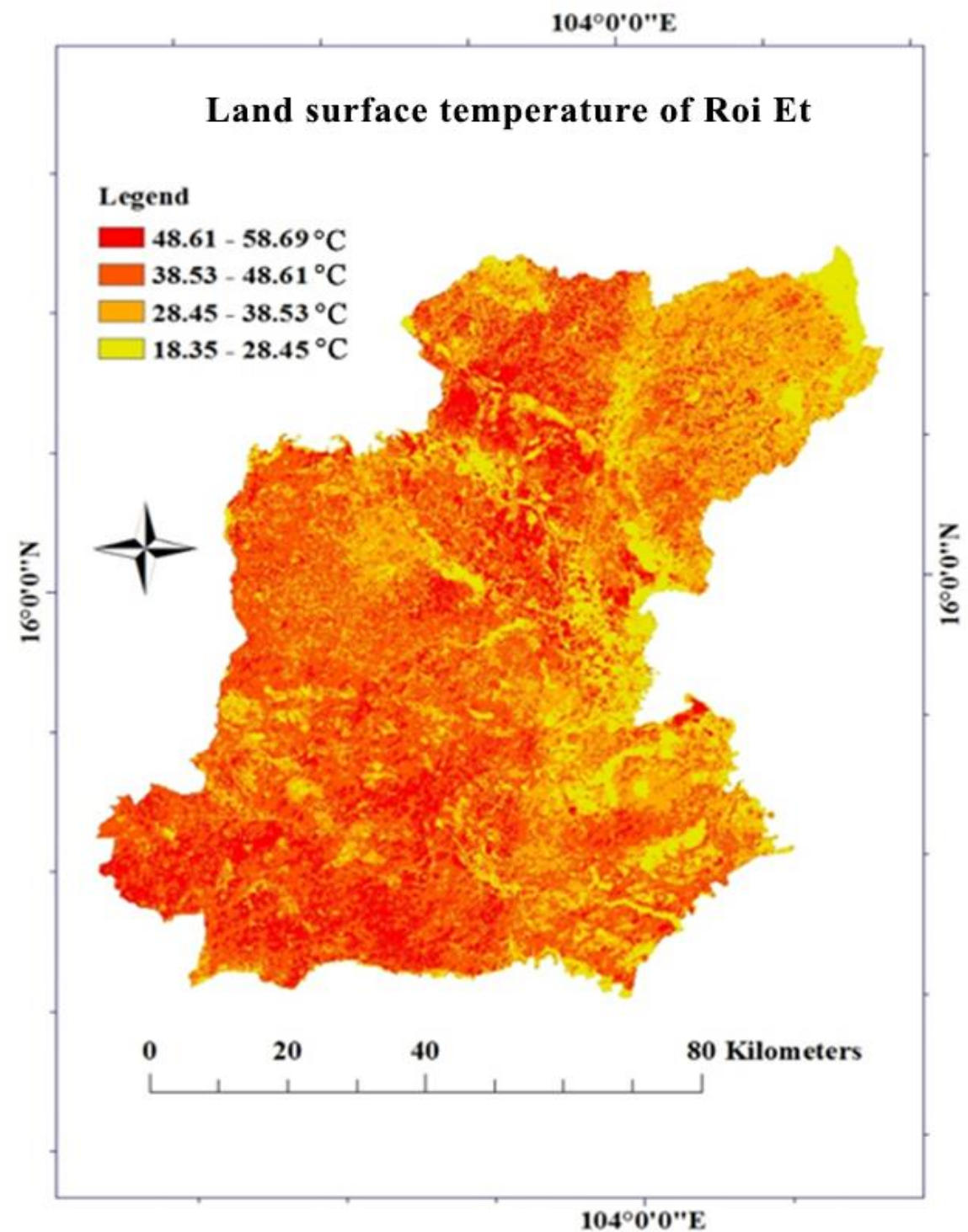

Fig. 4. Land surface temperature of Roi Et province. 


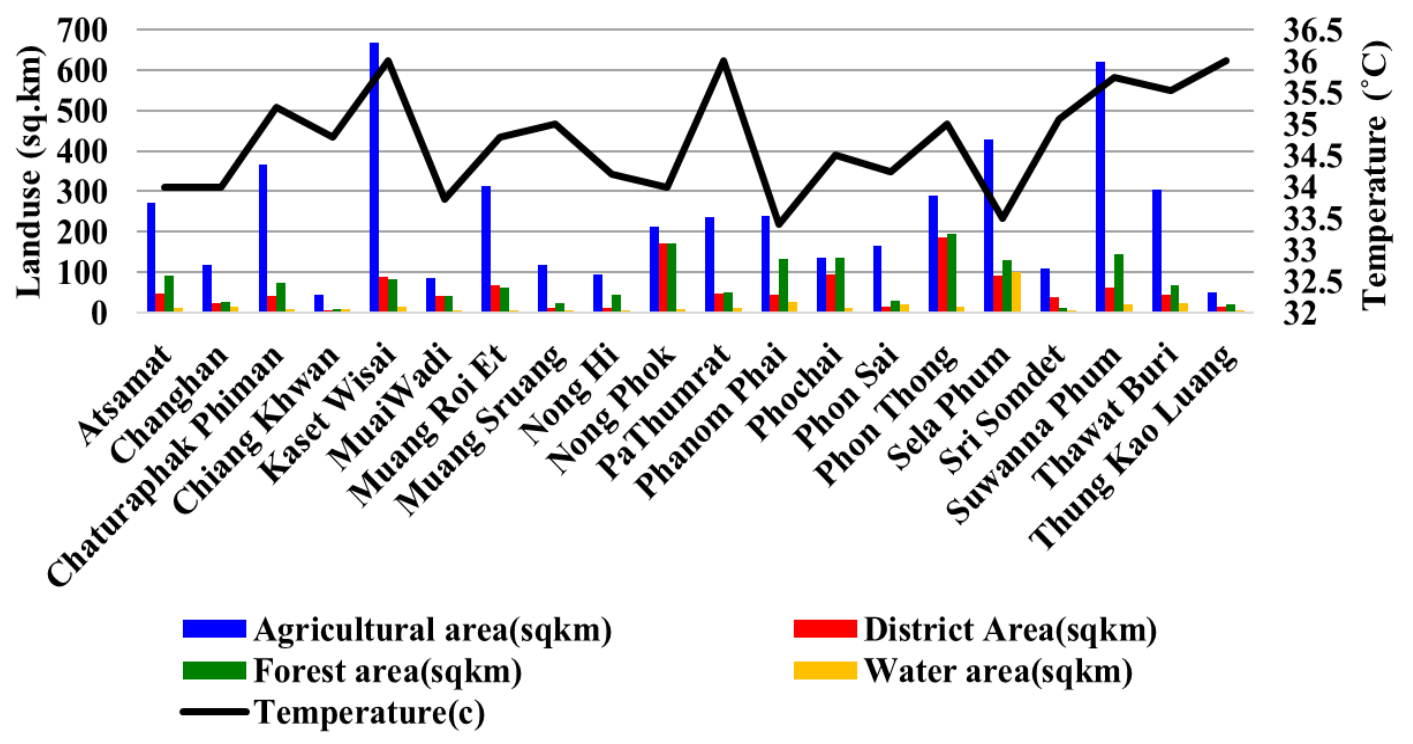

Fig. 5. Temporal variation land surface temperature of Roi Et province.

\section{CONCLUSIONS}

As of today, global climate has severely and frequently changed. Such change is reflected by El Nino and La Nina, which occur more frequently, including the land surface temperature, which seems to increase continuously. Through this research, the land surface temperature value analysed by the satellite data was compared to the daily temperature measured by the TMD station located in Roi Et, and an error of $4.07 \%$ was found. The value of the land surface temperature analysed by the satellite data was $34.74^{\circ} \mathrm{C}$, while the temperature data from the TMD station was $32.00^{\circ} \mathrm{C}$. Therefore, a hypothesis was set that the TMD temperature measurement station located in each district of Roi Et province is available for one to two stations, and the district with the maximum TMD temperature measurement stations (two stations) is Muang Roi Et (see Fig.1). It can be noted that the Thai Meteorological Department's temperature data from the one to two stations may not be enough to represent each district and the entire province. As for the land surface temperature data analysed by the satellite, they were analysed from every inch of the Roi Et province area.

\section{ACKNOWLEDGEMENTS}

This research was financially supported by the Faculty of Science, Mahasarakham University (Grant year 2020).

\section{R E F E R E N C E S}

Barsi, J.A., Schott, J.R., Hook, S.J., Raqueno, N.G., Markham, B.L., \& Radocinski, R.G. (2014). Landsat-8 thermal infrared sensor (TIRS) vicarious radiometric calibration. Remote Sensing, 6(11), 11607-11626.

Capodici, F., Cammalleri, C., Francipane, A., Ciraolo, G., La Loggia, G., \& Maltese, A. (2020). Soil Water Content Diachronic Mapping: An FFT Frequency Analysis of a Temperature-Vegetation Index. Geosciences, 10(1), 23. 
Chen, F., Yang S., Su, Z., \& He, B. (2015). A new single-channel method for estimating land surface temperature based on the image inherent information: The HJ-1B case. ISPRS Journal of Photogrammetry and Remote Sensing, 101, 80-88.

Dechaphongthana, W., Karnchanasutham, S., Nualchawee, K., \& Intarawichian N. (2016). The relationships between land surface temperature and NDVI of paddy rice areas in stages of growth from satellite data. Journal of Geoinformation Technology of Burapha University, 1(2), 14-30. (in Thai)

Du, C., Ren, H., Qin, Q., Meng, J., \& Zhao, S. (2015). A practical split-window algorithm for estimating land surface temperature from Landsat 8 data. Remote Sensing, 7(1), 647-665.

IPCC. (2019). An IPCC Special report on climate change, desertification, land degradation, sustainable land management, food security, and greenhouse gas fluxes in terrestrial ecosystems (ISBN 978-92-9169-1548) Retrieved from https://www.ipcc.ch/site/ assets/uploads/sites//02/2020/4SPM_Updated-Jan.20pdf

Khandelwal, S., Goyal, R., Kaul, N., \& Mathew, A. (2018).Assessment of land surface temperature variation due to change in elevation of area surrounding Jaipur, India. Egyptian Journal of Remote Sensing and Space Science, 21(1), 87-94

Laosuwan, T., \& Uttaruk, P. (2014). Estimating tree biomass via remote sensing, MSAVI 2, and Fractional Cover model. IETE Technical Review, 31(5), 362-368.

Laosuwan, T., Gomasathit, T., \& Rotjanakusol, T. (2017). Application of remote sensing for temperature monitoring: The technique for land surface temperature analysis. Journal of Ecological Engineering, 18 (3), 53-60.

Lemke, P., Ren, J., Alley, R.B., Allison, I., Carrasco, J., Flato, G., ...Zhang, T. (2007). Climate Change 2007: The Physical Science Basis. Contribution of Working Group I to the Fourth Assessment Report of the Intergovernmental Panel on Climate Change. Cambridge University Press, Cambridge, United Kingdom and New York, NY, USA.

Li, X., Zhou, W., \& Ouyang, Z. (2013). Relationship between land surface temperature and spatial pattern of greenspace: What are the effects of spatial resolution? Landscape and Urban Planning. 114, 1-8.

Mathew, A., Khandelwal, S., \& Kaul, N. 2017. Investigating spatial and seasonal variations of urban heat island effect over Jaipur city and its relationship with vegetation, urbanization and elevation parameters. Sustainable Cities and Society, 35, 157-177.

McMillin, L. M. (1975). Estimation of sea surface temperature from two infrared window measurements with different absorption. Journal of Geophysical Research, 20, 11587-11601.

Miles, V., \& Esau, I. (2017). Seasonal and Spatial Characteristics of Urban Heat Islands (UHIs) in Northern West Siberian Cities. Remote Sensing, 9(10), 1-15.

Mukhelif, A., Al. Ammar, K., \& Al Jooburi, M. (2016). The seasonal variation of the urban heat island effect and estimating the Human Discomfort Index at the City of Hillah. Pure and Applied Sciences, 24(2), 423434.

Nill, L., Ullmann, T., Kneisel, C., Sobiech-Wolf, J., \& Baumhauer, R. (2019). Assessing Spatiotemporal Variations of Landsat Land Surface Temperature and Multispectral Indices in the Arctic Mackenzie Delta Region between 1985 and 2018. Remote Sensing, 11(19), 2329.

Prohmdirek, T., Chunpang, P., \& Laosuwan, T. (2020). The Relationship between Normalized Difference Vegetation Index and Canopy Temperature that affects the urban heat island phenomenon. Geographia Technica, 15(2), 222-234.

Rajeshwari, A. \& Mani, N.D. (2014). Estimation of land surface temperature of Dindigul district using Landsat 8 data. International Journal of Research in Engineering and Technology, 3 (5), 122-126.

Ren, H., Du, C., Liu, R., Qin, Q., Yan, G., Li, Z. \& Meng, J. (2015). Atmospheric water vapor retrieval from Landsat 8 thermal infrared images. Journal of Geophysical Research Atmospheres, 120(5), 1723-1738.

Ren, H., Yan, G., Chen, L., \& Li, Z.L. (2011). Angular effect of MODIS emissivity products and its application to the split-window algorithm. ISPSR J. Photogramm, 66, 498-507.

Rotjanakusol, T., \& Laosuwan, T. (2018). Estimation of land surface temperature using Landsat satellite data: A case study of Mueang Maha Sarakham district, Maha Sarakham province, Thailand for the years 2006 and 2015. Scientific Review Engineering and Environmental Sciences, 27 (4), 401-409.

Rotjanakusol, T., \& Laosuwan, T. (2019). An Investigation of drought around Chi Watershed during ten-year period using Terra/MODIS data. Geographia Technica, 14(2), 74-83.

Rotjanakusol, T., \& Laosuwan, T. (2020). Model of relationships between land surface temperature and urban built-up areas in Mueang Buriram district, Thailand. Polish Journal of Environmental Studies, 29(5), 37833790 .

Rotjanakusol, T., \& Laosuwan, T. (2020). Surface water body extraction using Landsat 8 images and different forms of physical models. The Scientific Journal of King Faisal University, Basic and Applied Sciences, 21(2), 218-223. 
Uttaruk, Y., \& Laosuwan, T. (2017). Drought detection by application of remote sensing technology and vegetation phenology. Journal of Ecological Engineering, 18(6), 115-121.

Uttaruk, Y., \& Laosuwan, T. (2018). Community forest for global warming mitigation: The technique for estimation of biomass and above ground carbon storage using remote sensing method. Agriculture and Forestry, 64(3), 47-57.

Uttaruk, Y., Laosuwan, T. (2020). Comparison of carbon storage measurement methods on Agroforestry Systems in Sakon Nakhon province, Northeast Thailand. The Scientific Journal of King Faisal University, Basic and Applied Sciences, 21(2), 95-99.

Valor, E., \& Caselles, V. (1996). Mapping land surface emissivity from NDVI: Application to European, African, and South American areas. Remote Sensing of Environment, 57 (3), 167-184.

Vlassova, L., Pérez-Cabello, F., Mimbrero, M., Llovería, R., \& García-Martín, A. (2014). Analysis of the relationship between land surface temperature and wildfire severity in a series of Landsat images. Remote Sensing, 6(7), 6136-6162.

Yue, W., Xu, J., Tan., W., \& Xu, L. (2007). The relationship between land surface temperature and NDVI with remote sensing: Application to Shanghai Landsat 7 ETM+ data. International Journal of Remote Sensing, 28(15), 3205-3226.

Yu, X., Guo, X., \& Wu, Z. (2014). Land surface temperature retrieval from Landsat 8 TIRS-Comparison between Radiative Transfer Equation-based method, split window algorithm and single channel method. Remote Sensing, 6(10), 9829-9852.

Zhang, X.X., Wu, P.F., \& Chen, B. (2010). Relationship between vegetation greenness and urban heat island effect in Beijing City of China. Procedia Environmental Sciences, 2, 1438-1450.

Zhang, Y., Gao, J., Wang. J. (2007). Detailed mapping of a salt farm from Landsat TM imagery using neural network and maximum likelihood classifiers: A comparison. International Journal of Remote Sensing, 28(10), 2077-2089. 